\title{
Protein Kinase $C$ Is Increased in the Liver of Humans and Rats with Non- Insulin-dependent Diabetes Mellitus: An Alteration Not due to Hyperglycemia
}

\author{
Robert V. Considine, * Mark R. Nyce, ${ }^{*}$ Lonnie E. Allen, * Luz Marina Morales, * Stuart Triester, ${ }^{*}$ Jose Serrano, * \\ James Colberg, ${ }^{\ddagger}$ Susan Lanza-Jacoby, ${ }^{\ddagger}$ and Jose F. Caro* \\ *Division of Endocrinology and Metabolism, Department of Medicine, and ${ }^{\ddagger}$ Department of Surgery, Jefferson Medical College of \\ Thomas Jefferson University, Philadelphia, Pennsylvania 19107
}

\begin{abstract}
We tested the hypothesis that liver protein kinase $\mathrm{C}$ (PKC) is increased in non-insulin-dependent diabetes mellitus (NIDDM). To this end we examined the distribution of PKC isozymes in liver biopsies from obese individuals with and without NIDDM and in lean controls. PKC isozymes $\alpha, \beta$, $\epsilon$ and $\zeta$ were detected by immunoblotting in both the cytosol and membrane fractions. Isozymes $\boldsymbol{\gamma}$ and $\delta$ were not detected. There was a significant increase in immunodetectable PKC- $\alpha$ (twofold), - $\epsilon$ (threefold), and $-\zeta$ (twofold) in the membrane fraction isolated from obese subjects with NIDDM compared with the lean controls. In obese subjects without NIDDM, the amount of membrane PKC isozymes was not different from the other two groups. We next sought an animal model where this observation could be studied further. The Zucker diabetic fatty rat offered such a model system. Immunodetectable membrane PKC- $\alpha,-\beta,-\epsilon$, and $-\zeta$ were significantly increased when compared with both the lean and obese controls. The increase in immunodetectable PKC protein correlated with a $40 \%$ elevation in the activity of PKC at the membrane. Normalization of circulating glucose in the rat model by either insulin or phlorizin treatment did not result in a reduction in membrane PKC isozyme protein or kinase activity. Further, phlorizin treatment did not improve insulin receptor autophosphorylation nor did the treatment lower liver diacylglycerol. We conclude that liver PKC is increased in NIDDM, a change that is not secondary to hyperglycemia. It is possible that PKCmediated phosphorylation of some component in the insulin signaling cascade contributes to the insulin resistance observed in NIDDM. (J. Clin. Invest. 1995. 95:2938-2944.) Key words: PKC isozymes • liver • insulin resistance • ZDF rat
\end{abstract}

\section{Introduction}

Insulin resistance is a hallmark of non-insulin-dependent diabetes mellitus (NIDDM) ${ }^{1}(1-9)$. Protein kinase C (PKC) has

Address correspondence to Robert V. Considine, Ph.D., Thomas Jefferson University, 1025 Walnut St., 813 College Building, Philadelphia, PA 19107. Phone: 215-955-8791; FAX: 215-955-2318.

Received for publication 15 December 1994 and in revised form 13 February 1995.

1. Abbreviations used in this paper: DAG, diacylglycerol; NIDDM, non-insulin-dependent diabetes mellitus; PKC, protein kinase $\mathrm{C}$; ZDF, Zucker diabetic fatty.

J. Clin. Invest.

(C) The American Society for Clinical Investigation, Inc. 0021-9738/95/06/2938/07 \$2.00

Volume 95, June 1995, 2938-2944 been implicated in the development of insulin resistance in a variety of isolated cell and tissue systems (10-14). Of particular interest to the present study, phorbol ester-induced activation of PKC in rat hepatocytes results in a reduction in insulinstimulated glycogen $(15,16)$ and lipid synthesis (15). More recently, insulin resistance was induced by transfection with PKC specific cDNA and subsequent activation of the expressed kinase in cultured cells (17). Although PKC-mediated phosphorylation and inactivation of the insulin receptor tyrosine kinase has been demonstrated in vitro $(18,19)$, other studies have suggested that receptor phosphorylation is not a requirement for activated PKC to cause insulin resistance $(20,21)$. It is therefore plausable to expect that PKC would be increased in tissue from NIDDM patients and that this increase could contribute to the observed insulin resistance. For this reason we have compared the distribution of PKC isozymes in liver from obese patients with NIDDM with that in obese or lean patients without NIDDM. The isozymes were also examined in Zucker diabetic fatty (ZDF) rat liver, a genetically derived animal model of type II diabetes (22). In addition, the effect of plasma glucose concentration on PKC activity, isozyme distribution, and diacylglycerol (DAG) content of the ZDF rat liver was investigated. The results suggest that PKC may be involved in insulin resistance; however, hyperglycemia does not appear to affect PKC metabolism in the liver.

\section{Methods}

Materials. Anti-PKC polyclonal antibodies and nitrocellulose-1 were obtained from GIBCO BRL (Grand Island, NY). Monoclonal antibodies for PKC- $\alpha,-\beta$, and $-\epsilon$ were purchased from Transduction Laboratories (Lexington, $\mathrm{KY}$ ). Horseradish peroxidase-linked anti-rabbit or antimouse antibody, enhanced chemiluminescence kit and DAG assay were from Amersham Corp. (Arlington Heights, Il). Electrophoresis reagents and the DC protein assay were obtained from Bio-Rad Laboratories, Inc. (Melville, NY). X-Omat film was from Eastman Kodak Co. (Rochester, NY). [ ${ }^{32}$ P]ATP was from New England Nuclear (Boston, MA). All other chemicals were purchased from either Sigma Chemical Co. (St. Louis, MO) or Fisher Scientific Co. (Pittsburgh, PA).

Human subjects. 15 individuals were studied: 5 obese with NIDDM, 5 obese without diabetes, and 5 lean subjects. All individuals signed informed consent. The characteristics of the study groups are presented in Table I. These subjects do not differ significantly from those studied previously by this laboratory (4). After opening the abdomen, a 1-2$\mathrm{g}$ biopsy was obtained from the left lobe of the liver and immediately frozen in liquid nitrogen. The tissue was stored at $-80^{\circ} \mathrm{C}$ until used.

Animals. ZDF rats (ZDF/Gmi $\left.{ }^{\mathrm{TM}}-f a / f a\right)$ and their lean littermates $\left(\mathrm{ZDF} / \mathrm{Gmi}^{\mathrm{TM}}\right.$ ) were purchased from Genetic Models Inc. (Indianapolis, IN). The obese Zucker $(f a / f a)$ rats were obtained from Charles River Breeding Laboratories, Inc. (Wilmington, MA). For simplicity of nomenclature the ZDF rat is referred to as obese/diabetic, the obese Zucker rats will be termed obese, and the lean ZDF rats will be called lean. All rats were male, age matched (10-12 wk), housed together, and fed a standard lab chow (Purina 5008; Purina Mills, Inc., St. Louis, MO) 
Table I. Clinical Data for Patients

\begin{tabular}{|c|c|c|c|}
\hline & Lean & Obese & Obese/diabetic \\
\hline Number and gender & 5 female & 5 female & 4 female, 1 male \\
\hline Age (yr) & $43 \pm 5$ & $37 \pm 3$ & $47 \pm 4$ \\
\hline Weight (kg) & $63 \pm 2$ & $126 \pm 8$ & $142 \pm 5$ \\
\hline Height (cm) & $165 \pm 2$ & $163 \pm 2$ & $166 \pm 2$ \\
\hline $\begin{array}{l}\text { Body mass index } \\
\left(\mathrm{kg} / \mathrm{m}^{2}\right)\end{array}$ & $23 \pm 1$ & $48 \pm 2$ & $52 \pm 2$ \\
\hline $\begin{array}{l}\text { Fasting plasma glucose } \\
(\mathrm{mg} / \mathrm{dl})\end{array}$ & $98 \pm 6$ & $100 \pm 9$ & $219 \pm 38$ \\
\hline $\begin{array}{l}\text { Fasting plasma insulin } \\
\qquad(\mu \mathrm{U} / \mathrm{ml})\end{array}$ & $9.3 \pm 1.8$ & $20.2 \pm 6.4$ & $43.7 \pm 10$ \\
\hline
\end{tabular}

Values represent the mean $\pm S E M$.

ad libitum until they were killed. After killing, the liver was immediately removed, frozen with liquid nitrogen, and stored at $-80^{\circ} \mathrm{C}$ until use.

Preparation of liver PKC. Approximately $100 \mathrm{mg}$ of frozen human liver or $\sim 0.7 \mathrm{~g}$ of rat liver was homogenized by polytron in $5 \mathrm{ml}$ icecold buffer containing the following $(\mathrm{mM}): 20$ Tris- $\mathrm{HCl}(\mathrm{pH} 7.5)$, 250 sucrose, 2 EGTA, $50 \beta$-mercaptoethanol, 0.1 tosyl-L-phenylalanine chloromethyl ketone, 0.1 tosyl-L-lysine chloromethyl ketone, 0.5 benzamidine, and $5 \mu \mathrm{g} / \mathrm{ml}$ aprotinin. The homogenate was centrifuged at $500 \mathrm{~g}$ for $5 \mathrm{~min}$ at $4^{\circ} \mathrm{C}$ to remove tissue debris. The homogenate was then centrifuged at $100,000 \mathrm{~g}$ for $60 \mathrm{~min}$ in a Sorval RC-6 (Dupont, Newtown, CT) at $4^{\circ} \mathrm{C}$. The resultant supernatant containing the cytosolic PKC was removed, aliquoted, and stored at $-80^{\circ} \mathrm{C}$. The pellets were resuspended in $2 \mathrm{ml}$ of the above homogenization buffer containing $1 \%$ Triton X-100. The membrane-associated PKC was extracted from the pellets by vigorous vortexing every $5 \mathrm{~min}$ for a total of $30 \mathrm{~min}$ on ice. The extract was centrifuged at $100,000 \mathrm{~g}$ for $60 \mathrm{~min}$, and the supernatant (membrane PKC) was aliquoted and stored at $-80^{\circ} \mathrm{C}$. Protein concentration was determined with the non-detergent-sensitive BioRad DC assay using bovine serum albumin as standard.

Western blot for PKC isozymes. Liver preparations from each experimental group were screened for PKC- $\alpha,-\beta,-\gamma,-\delta,-\epsilon$, and $-\zeta$ with either polyclonal (GIBCO BRL) or monoclonal antibodies (Transduction Laboratories) raised against peptides corresponding to unique sequences of each isozyme. Total cytosolic protein or total membrane protein extracts (10-40 $\mu \mathrm{g}$ ) were solubilized in Laemmli buffer and then separated by electrophoresis through a $10 \%$ polyacrylamide gel. As a positive control, $10 \mu \mathrm{g}$ of mouse brain cytosol protein, prepared as described above, was included on each gel. The separated proteins were transferred to nitrocellulose- 1 for $2-3 \mathrm{~h}$ at $75 \mathrm{~V}$ in the cold. The filters were blocked per the vendor's specifications. A concentration of $2-5 \mu \mathrm{g} / \mathrm{ml}$ for the polyclonal and $1 \mu \mathrm{g} / \mathrm{ml}$ for the monoclonal antibody was sufficient to obtain a strong signal. At these concentrations the antibody-antigen reaction was linear over a range of protein from 1 to $50 \mu \mathrm{g}$. Blots were exposed to secondary antibody (either horseradish peroxidase-linked anti-rabbit or anti-mouse; 1:4,000 dilution) for $60 \mathrm{~min}$ at room temperature. Immunodetection was performed with an enhanced chemiluminescence kit per manufacturer's instructions, and the filters were exposed to X-Omat film for 1-30 min. Sample band intensity was measured with a DeskTop Scanner and software from PDI (Huntington Station, NY) and expressed as a fraction of the amount of isozyme present in $10 \mu \mathrm{g}$ of the cytosolic fraction of the mouse brain preparation on each gel.

PKC activity. PKC activity was measured as described (13) with slight modification. The buffer consisted of $25 \mathrm{mM}$ Hepes ( $\mathrm{pH} 7.5$ ) containing $10 \mathrm{mM} \mathrm{MgCl}, 0.1 \mathrm{mM}\left[\gamma^{32}\right.$ P]ATP ( $\left.200 \mathrm{cpm} / \mathrm{pmol}\right)$, and $200 \mu \mathrm{g} / \mu \mathrm{l}$ histone $\mathrm{Hl}(100 \mu \mathrm{l}$ total $)$. PKC-mediated phosphorylation was defined as the activity in the presence of $250 \mu \mathrm{g} / \mathrm{ml}$ phosphatidylserine, $10 \mu \mathrm{g} / \mathrm{ml}$ diolein, and $0.75 \mathrm{mM} \mathrm{CaCl}_{2}$ minus that in the presence of $0.5 \mathrm{mM}$ EGTA. The phosphotidylserine and diolein were dissolved in chloroform that was evaporated to dryness with $\mathrm{N}_{2}$. The lipids were then resuspended in $25 \mathrm{mM}$ Hepes by sonication. The reaction was allowed to proceed for $20 \mathrm{~min}$ at $30^{\circ} \mathrm{C}$ and was terminated by spotting the mixture onto Whatman P-81 phosphocellulose paper. The paper was washed three times in $75 \mathrm{mM}$ phosphoric acid, and the strips were counted in ReadySafe scintillation cocktail (Beckman, Fullerton, CA). PKC activity is expressed as picomoles of ${ }^{32} \mathrm{P}$ incorporated into histone per minute per milligram of protein.

Insulin treatment. To lower plasma glucose, three obese/diabetic rats were administered 10-12 U of Ultralente insulin (Eli Lilly \& Co., Indianapolis, IN) per day subcutaneously as a single dose in the morning. As a control, three additional obese/diabetic rats were given an equal volume of saline. Blood glucose was monitored daily before the insulin injection using an Accu-Chek Easy glucose meter (model no. 788).

Phlorizin treatment. Six obese/diabetic rats were given phlorizin $(0.4 \mathrm{~g} / \mathrm{kg}$ body wt dissolved in propylene glycol) by subcutaneous injection every $8 \mathrm{~h}$ over a 10-d period. As a control six additional obese/ diabetic rats received vehicle alone. Blood glucose was monitored daily in the morning (Accu-Chek Easy, model no. 788).

Insulin receptor autophosphorylation. Wheat germ agglutinin-purified insulin receptors were prepared as described previously $(4,13)$. Solubilized receptors $(5 \mu \mathrm{g})$ were diluted to $100 \mu \mathrm{l}$ in $50 \mathrm{mM}$ Hepes (pH 7.4), $5 \mathrm{mM} \mathrm{MnCl}$. Receptors were preincubated in the presence or absence of $10^{-7} \mathrm{M}$ or $10^{-9} \mathrm{M}$ insulin for $15 \mathrm{~min}$ at room temperature. Phosphorylation was initiated by the addition of $\left[\gamma-{ }^{32} \mathrm{P}\right]$ ATP $(25 \mu \mathrm{M}$ final concentration) and allowed to proceed for $10 \mathrm{~min}$. The reaction was stopped by the addition of $2 \times$ Laemmli buffer followed by boiling for $5 \mathrm{~min}$. Insulin receptor $\beta$-subunit was separated from the other protein by SDS-PAGE, and the amount of autophosphorylation was quantitated by phosphoimager analysis (Molecular Dynamics, Sunnyvale, CA). The insulin-binding capacity of each preparation was determined as previously described (4) and was used to normalize the autophosphorylation data.

Diacylglycerol assay. sn-1,2-diacylglycerol was extracted from the liver by the method of Bligh and Dyer (23). $0.25 \mathrm{~g}$ of frozen tissue was homogenized in $3 \mathrm{ml}$ of chloroform:methanol (1:2, vol/vol), followed by the addition of $1 \mathrm{ml}$ of $1 \mathrm{M} \mathrm{NaCl}$ and then $1 \mathrm{ml}$ of chloroform with vortexing. $1 \mathrm{ml}$ of $1 \mathrm{M} \mathrm{NaCl}$ was then added to break the phases. The samples were centrifuged at $3,000 \mathrm{~g}$ for $2 \mathrm{~min}$, and the lower chloroform phase taken for analysis of DAG by the method of Preiss et al. (24) using a kit available from Amersham Corp.

Miscellaneous. Serum glucose was determined by using a Beckman Glucose 2 analyzer and following the manufacturer's instructions. Insulin levels were measured by RIA in the laboratory of Dr. Guenther Boden (Temple University, Philadelphia, PA). All data, unless otherwise noted, are expressed as the mean \pm SEM. Statistical analyses were performed using the StatView software package for Macintosh. $P$ $<0.05$ in one-way ANOVA and unpaired $t$ test comparisons was taken as statistically significant.

\section{Results}

PKC isozymes detected in human liver. Liver preparations from lean, obese, and obese/diabetic individuals were screened for the presence of PKC isozymes $\alpha, \beta, \gamma, \delta, \epsilon$, and $\zeta$. Immunoblotting of both cytosol and membrane fractions with the polyclonal antibodies (up to $100 \mu \mathrm{g}$ total protein) failed to detect immunoreactive species corresponding to PKC $-\gamma$ or $-\delta$ in any experimental group. This did not appear to be due to poor antibody reactivity, as all isozymes were present in the mouse brain control (data not shown). Three isoforms of PKC were detected in human liver using the polyclonal antibodies. PKC- $\alpha$ appeared as a single band migrating with an apparent molecular mass of $80 \mathrm{kD}$. PKC- $\epsilon$ appeared as a $\sim 90-\mathrm{kD}$ band in each experimental group. PKC- $\zeta$ migrated as two distinct bands of $\sim 80$ and 70 

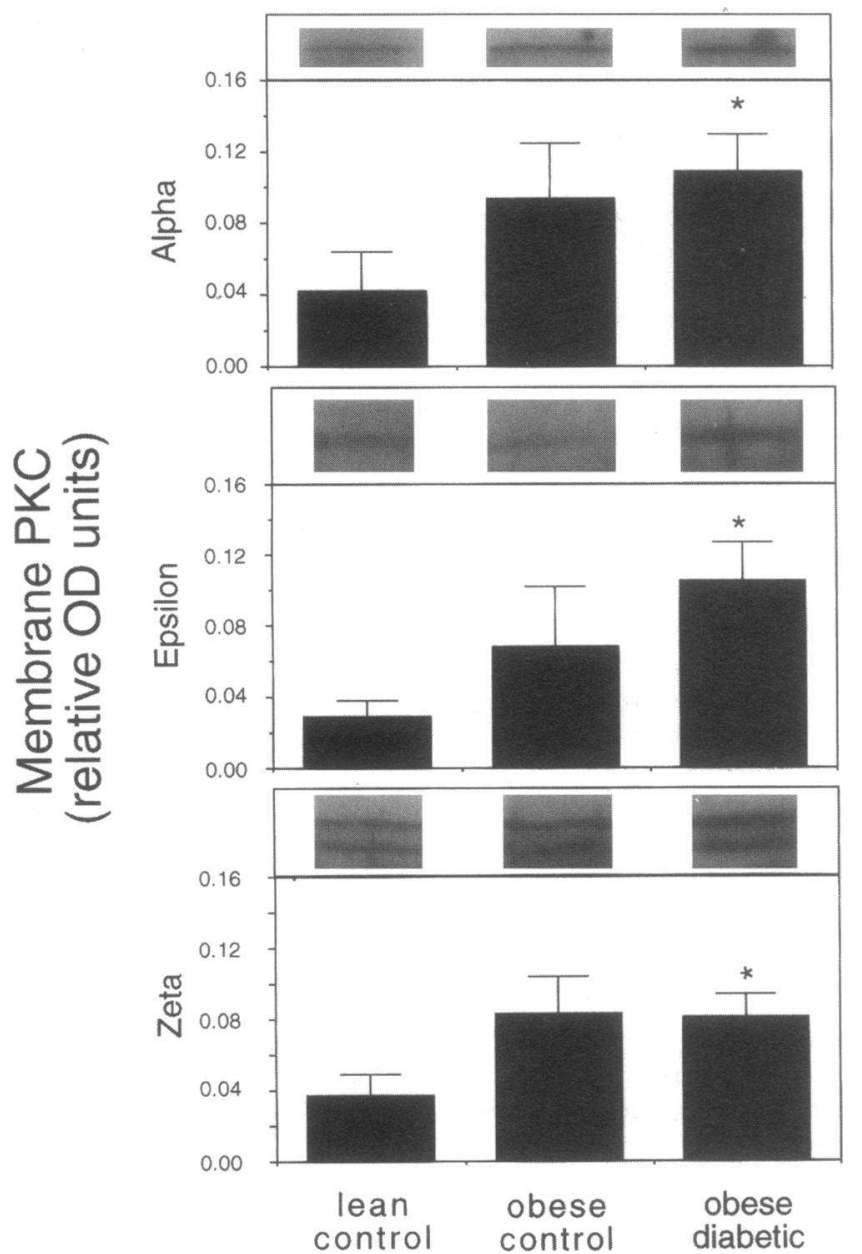

Figure 1. Immunodetection of membrane-associated PKC- $\alpha,-\epsilon$, and $-\zeta$ in liver from lean, obese, and obese/diabetic patients. Representative bands for each patient group are illustrated above the bar graph. The band density was measured by scanning densitometry in reference to the amount of isozyme present in the mouse brain control. Values represent the mean \pm SEM for five patients in each group. ${ }^{*} P<0.05$; compared with the amount of isozyme in the lean group.

$\mathrm{kD}$, respectively. Band identity for each isozyme was confirmed by competition experiments in which the antibody was preincubated with the peptide against which it was raised before exposure to the blot. Although the polyclonal antibody failed to detect PKC- $\beta$ in the human liver, a band of apparent molecular mass of $80 \mathrm{kD}$ was detected by monoclonal antibody in each experimental group.

Distribution of PKC isozymes in human liver. The amount of immunodetectable PKC isozyme in each liver preparation was measured by densitometry and normalized as a fraction of the amount of isozyme present in the mouse brain preparation. As illustrated in Fig. 1, membrane PKC- $\alpha,-\epsilon$ and $80-\mathrm{kD} \zeta$ in the liver of the obese/diabetic individuals was elevated over that present in the lean subject liver preparations $(P<0.05)$. The $70-\mathrm{kD} \zeta$ isozyme was also increased in the obese/diabetic subjects, although not significantly $(0.04 \pm 0.02,0.07 \pm 0.01$, and $0.07 \pm 0.01$ relative OD units for the lean, obese, and obese/ diabetic, respectively). The amount of membrane PKC- $\alpha,-\epsilon$, and $-\zeta$ detected in the obese subject liver membrane fractions
Table II. Characteristics of the Animal Groups

\begin{tabular}{lccc}
\hline & Lean & Obese & Obese/diabetic \\
\hline $\begin{array}{l}\text { Number } \\
\text { Weight (g) }\end{array}$ & 9 & 7 & 10 \\
$\begin{array}{l}\text { Fed plasma glucose } \\
(\mathrm{mg} / \mathrm{dl})\end{array}$ & $296 \pm 9$ & $425 \pm 10$ & $369 \pm 9$ \\
$\begin{array}{l}\text { Fed plasma insulin } \\
(\mathrm{ng} / \mathrm{ml})\end{array}$ & $146 \pm 4$ & $189 \pm 23$ & $514 \pm 19$ \\
& $2.0 \pm 0.3$ & $11.0 \pm 3.4$ & $5.0 \pm 0.6$ \\
\hline
\end{tabular}

Values represent the mean $\pm S E M$ for the indicated number of animals.

was not different from either the lean control or the obese/ diabetic groups. The amount of cytosolic PKC- $\alpha(0.06 \pm 0.03$, $0.09 \pm 0.03$, and $0.09 \pm 0.01),-\epsilon(0.03 \pm 0.01,0.02 \pm 0.01$, and $0.03 \pm 0.01), 70-\mathrm{kD} \zeta(0.13 \pm 0.05,0.15 \pm 0.03,0.18 \pm 0.01)$, or $80-\mathrm{kD} \zeta(0.06 \pm 0.03,0.05 \pm 0.01,0.04 \pm 0.01$ relative $\mathrm{OD}$ units $)$ was not significantly different in the lean, obese, and obese/ diabetic groups, respectively.

Distribution of PKC isozymes in rat liver. Cytosol and membrane fractions were prepared from lean, obese, and obese/ diabetic rat liver in a manner similar to that for the human liver as described above. The physiological characteristics of the three animal groups are outlined in Table II.

As observed in human liver there was significantly more PKC- $\alpha,-\epsilon$, and $-\zeta$ present in the membrane fraction isolated from the obese/diabetic rats than in the membrane fraction isolated from the lean rats (Fig. 2 and Table III). In contrast to our findings in human liver, the amount of these PKC isozymes in the obese rat liver membrane fractions was identical to that in the lean rats and was significantly different from that in the obese/diabetic animals. These findings were confirmed using monoclonal antibodies for PKC- $\alpha$ and $-\epsilon$ (data not shown). In addition, using a monoclonal antibody for detection, there was significantly more PKC- $\beta$ in the membrane fraction isolated from the obese/diabetic group compared with the lean. There was no difference in the amount of cytosolic PKC- $\alpha$, $-\beta,-\epsilon$, or $-\zeta$ among the three groups of rats (Table III).

$P K C$ activity in rat liver. Further evidence for the differen-

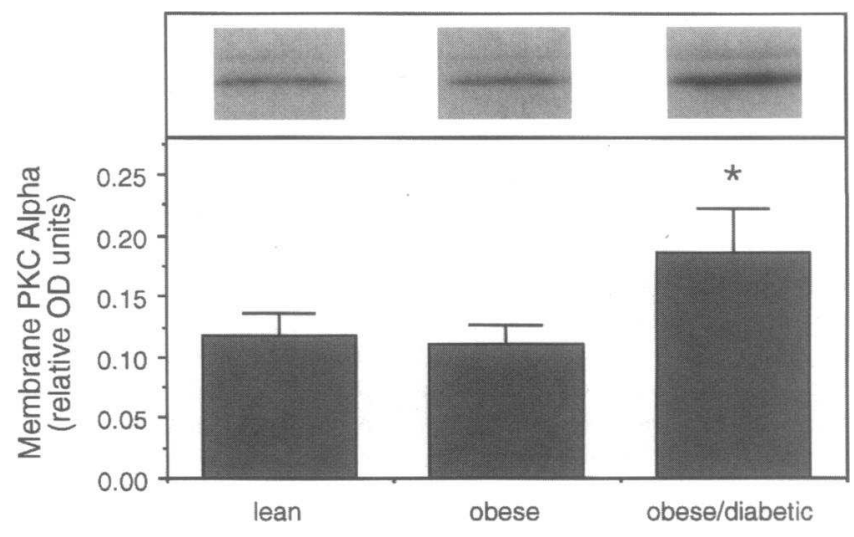

Figure 2. Membrane PKC- $\alpha$ is increased in liver of obese/diabetic rats. Data were generated as described in Fig. 1. Representative band density is illustrated above the graph. Note that in contrast to obese humans (Fig. 1), PKC- $\alpha$ is not elevated in obese rat membranes. ${ }^{*} P<0.05$; compared with the amount of isozyme in the lean or obese group. 
Table III. PKC Isozymes in Rat Liver

\begin{tabular}{cccc}
\hline Isozyme & Lean & Obese & Obese/diabetic \\
\hline PKC- $\beta$ & & & \\
Cytosol & $0.08 \pm 0.02$ & $0.10 \pm 0.03$ & $0.11 \pm 0.02$ \\
Membrane & $0.12 \pm 0.02$ & $0.11 \pm 0.02$ & $0.19 \pm 0.03^{*}$ \\
PKC- $\epsilon$ & & & \\
Cytosol & $0.02 \pm 0.01$ & $0.03 \pm 0.01$ & $0.04 \pm 0.01$ \\
Membrane & $0.014 \pm 0.001$ & $0.020 \pm 0.006$ & $0.040 \pm 0.008^{*}$ \\
PKC- $\zeta(80 \mathrm{kD})$ & & & \\
Cytosol & $0.06 \pm 0.01$ & $0.08 \pm 0.02$ & $0.07 \pm 0.01$ \\
Membrane & $0.013 \pm 0.002$ & $0.013 \pm 0.004$ & $0.029 \pm 0.007 *$ \\
PKC- $\zeta(70 \mathrm{kD})$ & & & \\
Cytosol & $0.25 \pm 0.05$ & $0.36 \pm 0.08$ & $0.29 \pm 0.05$ \\
Membrane & $0.06 \pm 0.01$ & $0.07 \pm 0.01$ & $0.12 \pm 0.02^{*}$ \\
& & & \\
\hline
\end{tabular}

Values expressed in relative OD units for at least seven animals in each group. $* P<0.05$ compared with the amount of isozyme in the lean group.

tial localization of $\mathrm{PKC}$ in obese/diabetic liver is provided by activity measurements in both the cytosol and membrane fractions. Activity was defined as the phosphorylation of histone protein in the presence of phosphatidylserine, diolein, and calcium minus that in the presence of EGTA. As shown in Fig. 3, there was a statistically significant $40 \%$ elevation in the activity of membrane-associated PKC in the obese/diabetic group. There was no difference in the activity of kinase in the cytosolic fractions (lean: 269 \pm 55 ; obese: 259 \pm 60 ; obese/diabetic: $242 \pm 46 \mathrm{pmol} / \mathrm{mg}$ per $\min$ ).

Insulin treatment of obese/diabetic rats. To evaluate the possibility that the increase in membrane PKC was due to the hyperglycemia in diabetes, three obese/diabetic rats were given supplemental insulin to lower blood sugar. As shown in Fig. 4 $A$, insulin was effective in keeping blood glucose near normal for the duration of the study. The insulin-treated animals gained more weight over the period than the controls ( $96 \pm 6$ vs. $26 \pm 10$ $\mathrm{g} ; P<0.05)$.

As illustrated in Fig. $4 B$, insulin treatment had no effect on the activity of membrane-associated PKC when compared with the activity in the untreated obese/diabetic controls. Immunoblotting failed to detect any difference in the amount of membrane-associated PKC- $\alpha(0.18 \pm 0.03),-\epsilon(0.02 \pm 0.01),-70 \mathrm{kD}$ $\zeta(0.2 \pm 0.04)$, or $-80-\mathrm{kDa} \zeta(0.05 \pm 0.01)$ compared with the

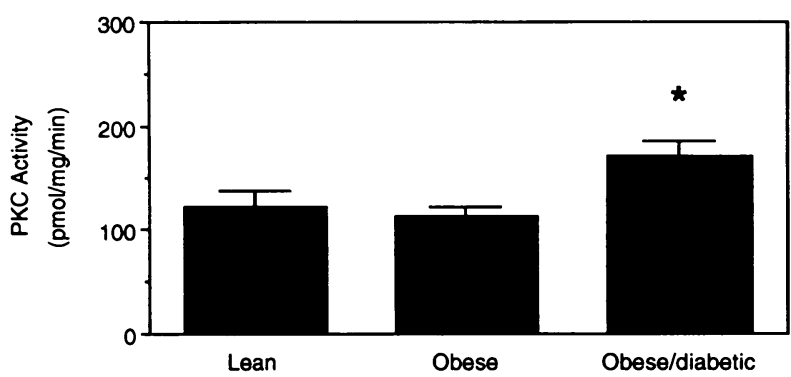

Figure 3. Membrane PKC activity is increased in obese/diabetic rat liver. Values represent the mean \pm SEM for at least seven animals in each group. $* P<0.05$; compared with either the lean or obese nondiabetic group.
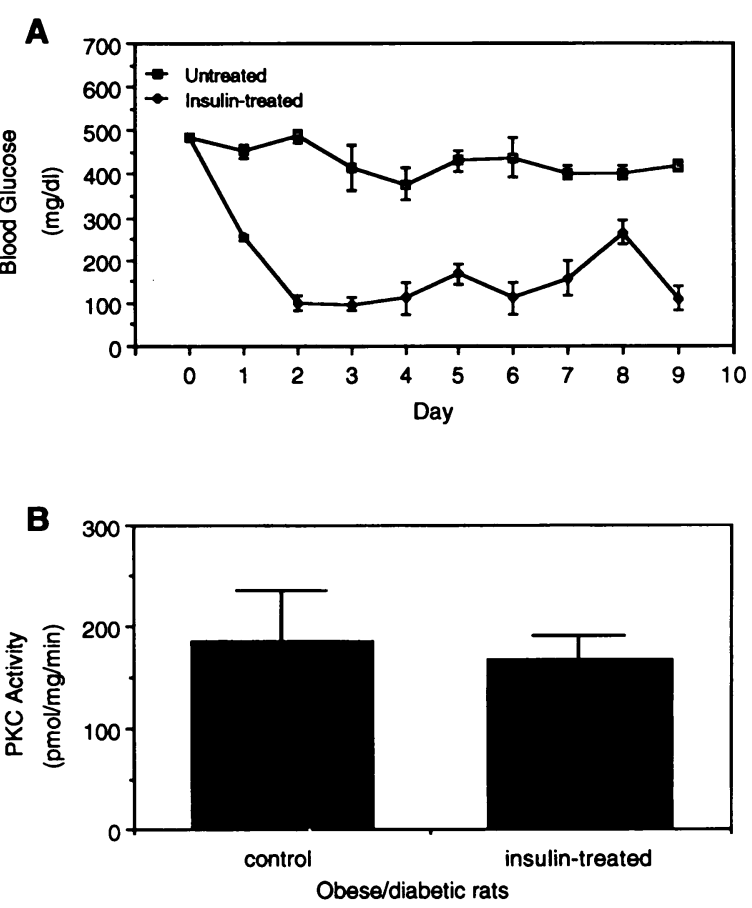

Figure 4. Reduction in plasma glucose with insulin treatment has no effect on membrane PKC activity in obese/diabetic rats. $(A)$ Insulin treatment significantly lowered blood glucose. Values represent the mean \pm SEM or mean \pm half the range for each point. $(B)$ Lowering plasma glucose had no effect on membrane PKC activity when compared with the control obese/diabetic animals receiving vehicle. Values represent the mean \pm SEM for three animals in each group.

untreated animals $(0.25 \pm 0.02,0.02 \pm 0.002,0.13 \pm 0.01$, and $0.04 \pm 0.001$ relative OD units for $\alpha, \epsilon, 70-\mathrm{kD} \zeta$, and $80-\mathrm{kD} \zeta$, respectively).

Insulin treatment resulted in a $64 \%$ increase in total liver DAG content. Animals receiving insulin had a liver DAG content of $935 \pm 95 \mathrm{pmol} / \mathrm{mg}$ tissue compared with $570 \pm 57 \mathrm{pmol} /$ $\mathrm{mg}$ tissue in the obese/diabetics receiving vehicle only ( $P$ $<0.05$; one-way ANOVA).

Phlorizin treatment of obese/diabetic rats. To address the potential effect of insulin and to evaluate further the role of circulating glucose on membrane $\mathrm{PKC}$, six obese/diabetic rats were administered phlorizin to reduce plasma glucose. As illustrated in Fig. $5 \mathrm{~A}$, phlorizin reduced circulating plasma glucose to near normal levels over a 10-d period. Insulin levels measured at killing were reduced $37 \%$ ( $P<0.05$; one-way ANOVA) in the treated rats compared with those receiving vehicle.

Normalization of plasma glucose with phorizin had no effect on membrane-associated PKC activity (Fig. 5 B). In addition, immunoblotting failed to detect any difference in the amount of membrane-associated PKC- $\alpha \quad(0.38 \pm 0.10),-\epsilon$ $(0.06 \pm 0.01),-70-\mathrm{kD} \zeta(0.20 \pm 0.01)$, or $-80-\mathrm{kD} \zeta(0.03 \pm 0.01)$ compared with the untreated animals $(0.39 \pm 0.12,0.05 \pm 0.01$, $0.19 \pm 0.03$, and $0.03 \pm 0.01$ relative OD units for PKC- $\alpha,-\epsilon, 70$ $\mathrm{kD} \zeta$, and $80-\mathrm{kD} \zeta$, respectively ).

In addition to the lack of a reduction in membrane PKC, phlorizin treatment did not improve the activity of the insulin receptor tyrosine kinase. As illustrated in Fig. 6, insulin-stimulated autophosphorylation was reduced $45 \%$ in the diabetic rat 

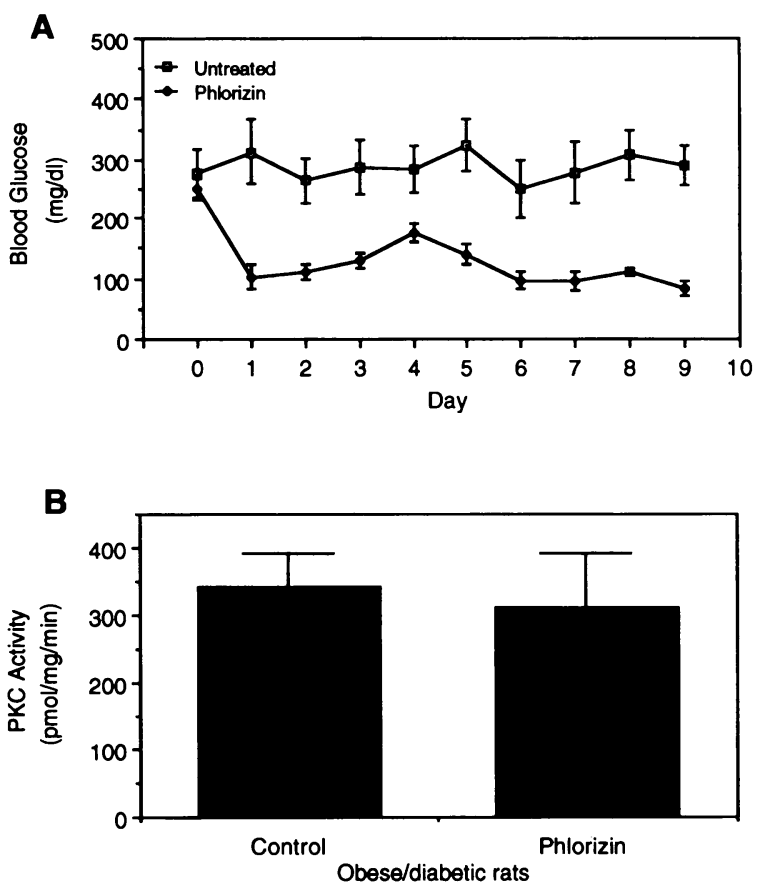

Figure 5. Phlorizin treatment lowers plasma glucose but has no effect on membrane PKC activity. (A) Phlorizin immediately lowered plasma glucose to an average value not different than that in lean nondiabetic rats. ( $B$ ) Membrane PKC activity after treatment was not different from that in obese/diabetic rats receiving vehicle only. Values represent the mean \pm SEM for six animals in each group.

liver compared with the lean rats, a situation not improved by phlorizin-induced euglycemia.

$D A G$ content of rat liver. The sn-1,2-diacylglycerol content of the obese/diabetic rat liver was determined as a possible contributing factor to the persistent PKC activation in these animals. Obese/diabetic rat liver contained three times as much DAG as that detected in the lean animal liver (Fig. 7). Phlorizin treatment did not result in a significant reduction in the amount of DAG. It should be noted that in the obese nondiabetic rat liver DAG was also elevated to a level not statistically different from that observed in the liver of the obese/diabetic animals.

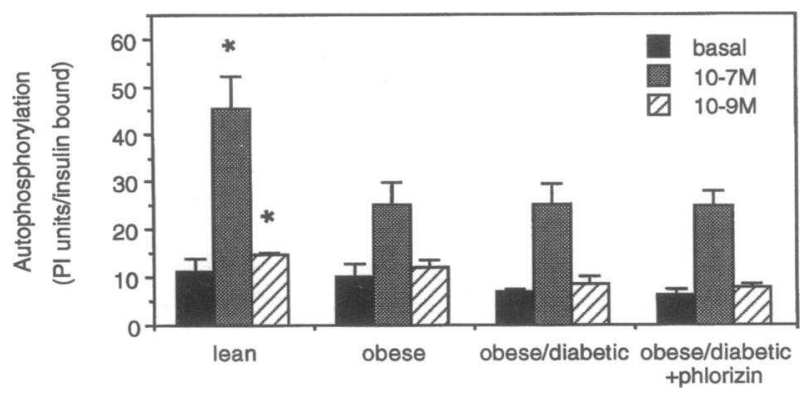

Figure 6. Insulin receptor tyrosine kinase activity after phlorizin treatment. Insulin receptors were prepared and autophosphorylation was determined as described in Methods. Phlorizin treatment did not improve receptor tyrosine kinase activity. Values represent the mean $\pm S E M$ for four lean, three obese, five obese/diabetic, and four phlorizin-treated animals. ${ }^{*} P<0.05$; compared with the other three groups.

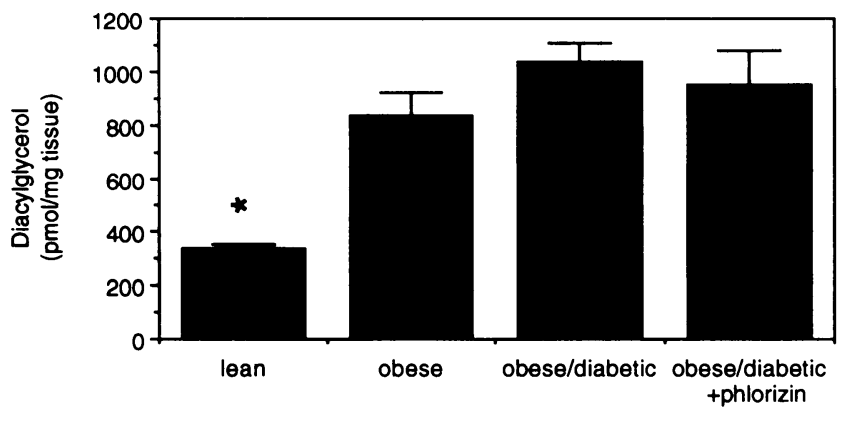

Figure 7. Diacylglycerol content of rat liver. sn-1,2-DAG was measured using the diacylglycerol kinase method. Values represent the mean \pm SEM for four lean, five obese, five obese/diabetic, and four phlorizin-treated animals. $* P<0.005$; compared with the other three groups.

\section{Discussion}

Using isozyme-specific antibodies, we identified PKC- $\alpha,-\beta$, $-\epsilon$, and $-\zeta$ in both human and rat liver. We were unable to detect the $-\gamma$ or $-\delta$ isoforms. To our knowledge this is the first characterization of the PKC isozymes in human liver. Further, our findings in the rat liver are in general agreement with those of other investigators $(25,26)$. Although the antibody for PKC$\zeta$ detected two bands $(27,28)$, the recent study of Ha and Exton (29) suggests that the $80-\mathrm{kD}$ band may result from crossreactivity with PKC- $\alpha$.

Having characterized the isozymes present, we next tested the hypothesis that liver PKC is increased in NIDDM. To this end we studied in humans and rats three metabolic states: obese with NIDDM, obese without NIDDM, and lean without NIDDM. PKC- $\alpha,-\epsilon$, and $-\zeta$ were elevated in the liver membranes of the obese/diabetics when compared with the lean controls in both humans and rats. PKC- $\beta$ was also elevated in the obese/diabetic rats; however, we were unable to quantitate this isozyme in humans because of limited supply of tissue. Immunodetectable PKC was different in the obese state between humans and rats. In human obesity the amount of PKC isozyme was not different either from the lean or obese/diabetics. Although this may be due in part to the small group of patients studied, it is of interest that obese human liver is more insulin resistant than that from lean individuals but less than that from diabetic subjects (4). In contrast to the human liver, the amount of PKC isozyme in the insulin-resistant obese rats $(30,31)$ was similar to that in the lean and significantly less than that in the obese/diabetic animals. These differences between the human and rat model could represent degrees of severity of insulin resistance. Alternatively, the insulin resistance of the obese Zucker rat liver could be due to a mechanism different from that of humans.

Because the alterations in liver PKC metabolism in the rat model of NIDDM were similar to those in the patients with NIDDM, elevated plasma glucose was examined as a possible cause of the increase in membrane PKC. Glucose-induced increases in DAG and membrane PKC have been demonstrated previously in different tissues (32-34), and inhibitors of PKC have been shown to prevent glucose-induced insulin resistance in rat fat cells (14). Cumulatively, these observations support a hypothesis that hyperglycemia leads to PKC activation and possibly insulin resistance. 
To determine if elevated glucose was the cause of the increase in membrane PKC, supplemental insulin was administered to the obese/diabetic rats. This treatment effectively lowered plasma glucose but not membrane PKC. In addition, insulin treatment resulted in a 64\% increase in liver DAG; however, it is difficult to determine if this DAG participates in the activation of PKC or is purely the result of metabolic processes (see below). Work from two laboratories has suggested that insulin can activate liver PKC $(35,36)$, and a possible stimulatory effect of elevated insulin on PKC cannot be ruled out in our studies.

To circumvent the uncertainties associated with insulin treatment, we used phlorizin to lower plasma glucose. This drug acts in the renal tubule to prevent glucose transport, resulting in enhanced glucose excretion $(37,38)$. Phlorizin treatment resulted in a normalized plasma glucose concentration that was maintained for $10 \mathrm{~d}$. Despite this rather lengthy euglycemic period, membrane PKC was not different from that in the obese/ diabetic controls administered vehicle. The sustained increase in membrane PKC may have been due to the elevation in liver DAG, which was unaltered by lowering blood glucose. However, it should be noted that the level of DAG in the obese rat liver was similar to that in the obese/diabetic animals, yet there was no significant elevation in membrane PKC. This observation suggests that the bulk of the DAG measured in liver is probably not associated with signaling but rather triglyceride synthesis stimulated by elevated insulin levels. In any respect, the elevation in membrane PKC in NIDDM liver does not appear to be due to hyperglycemia as would be suggested by the studies described above.

One other recent study examined the distribution of PKC isozymes in diabetic rat liver (26). Streptozotocin-induced diabetes increased the amount of PKC- $\alpha$ and $-\beta$ II in both the cytosol and membrane fraction and PKC- $\epsilon$ in the membrane fraction only. Insulin treatment of the diabetic animals reduced cytosolic PKC- $\alpha$ and $-\beta$ II and decreased membrane PKC- $\epsilon$ to below that of normal control animals. One major difference between the study of Tang et al. (26) and the present one is that the diabetic state is chemically induced and characterized by elevated plasma glucose with little or no circulating insulin. In this case changes in PKC may be due to the hyperglycemia, and therefore would be reversible with normalization of plasma glucose with insulin.

If the elevation in membrane PKC in insulin-resistant liver is not due to hyperglycemia, what are the other possibilities? Differences in the lipid composition of, or the microsomal contribution from other organelles to, the crude membrane preparation cannot be ruled out in this study. An alternative membranerelated possibility may reside in the phosphoinositide signal cascade. We have documented previously an increase in liver phosphatidylinositol 4,5-bisphosphate specific phospholipase C activity in NIDDM (39). This would result in increased $\mathrm{IP}_{3}$ and thus $\mathrm{Ca}^{2+}$, which has been shown to induce insulin resistance (40). This would also increase DAG and thus PKC activation.

The second possibility may involve insulin and insulin resistance. Kanety et al. (41) have documented recently that hyperinsulinemia in the sand rat model of NIDDM led to impairment in insulin receptor function. If PKC is activated by insulin (35, $36,42,43$ ), it could also function as the feedback switch responsible for turning off the insulin receptor.

The final possibility is that the increase in PKC is primary to NIDDM. This is highly unlikely because at least one alteration we believe to be due to the increase in PKC, namely the decrease in insulin receptor tyrosine kinase activity, is reversible after weight loss and improvement in insulin action (44). The fact that PKC did not decrease after insulin- or phlorizin-induced euglycemia in still insulin-resistant animals is not inconsistent with the notion that PKC would normalize with weight loss, exercise, or pharmacologic therapy aimed to improve insulin action.

What is the mechanism through which PKC would contribute to or cause insulin resistance? Most work has focused on PKC-mediated serine/threonine phosphorylation of the insulin receptor resulting in inactivation of the tyrosine kinase and the development of insulin resistance $(10-15,17-19)$, although this finding has not been universal $(16,45)$. Interestingly, Anderson and Olefsky (20) demonstrated a PMA-mediated inhibition of the insulin receptor tyrosine kinase and an increase in insulin resistance in cells expressing a truncated receptor lacking the major PKC phosphorylation site. Along similar lines, the work of Zachayus et al. (21) suggests that although PMAactivated $\mathrm{PKC}$ results in insulin resistance in permeabilized fetal hepatocytes, PKC is not directly responsible for the increase in serine phosphorylation of the insulin receptor. These studies suggest that the role of PKC in insulin resistance may not be the result of a direct interaction of the kinase with the receptor. Other possibilities could include PKC-mediated activation of another kinase or an insulin receptor specific phosphatase. Further work is necessary to determine the exact mechanism through which PKC contributes to insulin resistance.

In summary, we have detected a significant elevation in the PKC isozymes $\alpha, \epsilon$, and $\zeta$ in liver tissue from both humans and rats with NIDDM. PKC- $\beta$ was also increased in the diabetic rat liver. The increase in isozyme protein is accompanied by an increase in membrane-associated PKC activity. The increase in membrane PKC does not appear to be due to hyperglycemia but to some other factor in the individual with insulin resistance. These observations support the hypothesis that aberrant PKC activity may result in insulin resistance.

\section{Acknowledgments}

The authors sincerely thank Karen Davis and Guenther Boden (Temple University, Philadelphia, PA) for the measurement of serum insulin, as well as Hope Phetteplace and Natalia Sedkova for their assistance with the animals.

This work was supported in part by grant R01 DK45592 and fellowship 1F32 DK08888 from the National Institutes of Health.

\section{References}

1. DeFronzo, R. A., R. C. Bonadonna, and E. Ferrannini. 1992. Pathogenesis of NIDDM. Diabetes Care. 15:318-368.

2. Caro, J. F., L. G. Dohm, W. J. Pories, and M. K. Sinha. 1989. Cellular alterations in liver, skeletal muscle, and adipose tissue responsible for insulin resistance in obesity and type II diabetes. Diabetes Metab. Rev. 5:665-689.

3. Kahn, C. R., and M. F. White. 1988. The insulin receptor and the molecular mechanism of insulin action. J. Clin. Invest. 82:1151-1156.

4. Caro, J. F., O. Ittoop, W. J. Pories, D. Meelheim, E. G. Flickinger, F. Thomas, M. Jenquin, J. F. Silverman, P. G. Khazanie, and M. K. Sinha. 1986. Studies on the mechanism of insulin resistance in the liver from humans with non-insulin-dependent diabetes. Insulin action and binding in isolated hepatocytes, insulin receptor structure, and kinase activity. J. Clin. Invest. 78:249-258.

5. Freidenberg, G. R., R. R. Henry, H. H. Klein, D. R. Reichart, and J. M. Olefsky. 1987. Decreased kinase activity of insulin receptors from adipocytes of non-insulin-dependent diabetic subjects. J. Clin. Invest. 79:240-250.

6. Sinha, M. K., W. J. Pories, E. G. Flickinger, D. Meelheim, and J. F. 
Caro. 1987. Insulin-receptor kinase activity of adipose tissue from morbidly obese humans with and without NIDDM. Diabetes. 36:620-625.

7. Arner, P., T. Pollare, H. Lithell, and J. N. Livingston. 1987. Defective insulin receptor tyrosine kinase in human skeletal muscle in obesity and type 2 (non-insulin-dependent) diabetes mellitus. Diabetologia. 30:437-440.

8. Caro, J. F., M. K. Sinha, S. M. Raju, O. Ittoop, W. J. Pories, E. G. Flickinger, D. Meelheim, and G. L. Dohm. 1987. Insulin receptor kinase in human skeletal muscle from obese subjects with and without non-insulin-dependent diabetes. $J$. Clin. Invest. 79:1330-1337.

9. Obermaier-Kusser, B., M. F. White, D. E. Pongratz, Z. Su, B. Ermel, C. Muhlbacher, and H. U. Haring. 1989. A defective intramolecular autoactivation cascade may cause the reduced kinase activity of the skeletal muscle insulin receptor from patients with non-insulin dependent diabetes mellitus. J. Biol. Chem. 264:9497-9504.

10. Takayama, S., M. F. White, V. Lauris, and C. R. Kahn. 1984. Phorbol esters modulate insulin receptor phosphorylation and insulin action in cultured hepatoma cells. Proc. Natl. Acad. Sci. USA. 81:7797-7801.

11. Takayama, S., M. F. White, and C. R. Kahn. 1988. Phorbol ester-induced serine phosphorylation of the insulin receptor decreases its tyrosine kinase activity. J. Biol. Chem. 263:3440-3447.

12. Turinsky, J., D. M. O'Sullivan, and B. P. Bayly. 1990. 1,2-Diacylglycerol and ceramide levels in insulin-resistant tissues of the rat in vivo. J. Biol. Chem. 265:16880-16885.

13. Karasik, A., P. L. Rothenberg, K. Yamada, M. F. White, and C. R. Kahn. 1990. Increased protein kinase $C$ activity is linked to reduced insulin receptor autophosphorylation in liver of starved rats. J. Biol. Chem. 265:10226-10231.

14. Muller, H. K., M. Kellerer, B. Ermel, A. Muhlhofer, B. Obermaier-Kusser, B. Vogt, and H. U. Haring. 1991. Prevention by protein kinase c inhibitors of glucose-induced insulin receptor tyrosine kinase resistance in rat fat cells. Diabetes. 40:1440-1448.

15. Caro, J. F., M. Jenquin, and S. Long. 1992. Effects of phorbol esters on insulin receptor function and insulin action in hepatocytes: evidence for heterogeneity. Mol. Cell. Biochem. 109:115-118.

16. Quentmeier, A., H. Daneschmand, H. Klein, K. Unthan-fechner, and I. Probst. 1993. Insulin-mimetic actions of phorbol ester in cultured adult rat hepatocytes. Lack of phorbol-ester-elicited inhibition of the insulin signal. Biochem. J. 289:549-555.

17. Chin, J. E., M. Dickens, J. M. Tavare, and R. A. Roth. 1993. Overexpression of protein kinase $\mathrm{C}$ isozymes $\alpha, \beta \mathrm{I}, \gamma$ and $\epsilon$ in cells overexpressing the insulin receptor. J. Biol. Chem. 268:6338-6347.

18. Bollag, G. E., R. A. Roth, J. Beaudoin, D. Mochly-Rosen, and D. E. Koshland. 1986. Protein kinase C directly phosphorylates the insulin receptor in vitro and reduces its protein-tyrosine kinase activity. Proc. Natl. Acad. Sci. USA. 83:5822-5824.

19. Lewis, R. E., L. Cao, D. Perregaux, and M. P. Czech. 1990. Threonine 1336 of the human insulin receptor is a major target for phosphorylation by protein kinase C. Biochemistry. 29:1807-1813.

20. Anderson, C. M., and J. M. Olefsky. 1991. Phorbol ester-mediated protein kinase $\mathrm{C}$ interaction with wild-type and $\mathrm{COOH}$-terminal truncated insulin receptors. J. Biol. Chem. 266:21760-21764.

21. Zachayus, J. L., G. Cherqui, and C. Plas. 1994. Protein kinase $\mathrm{C}$ and insulin receptor $\beta$-subunit serine phosphorylation in cultured foetal rat hepatocytes. Mol. Cell. Endorinol. 105:11-20.

22. Peterson, R. G., W. N. Shaw, M. Neel, L. A. Little, and J. Eichberg. 1990 Zucker diabetic fatty rat as a model for non-insulin-dependent diabetes mellitus. ILAR News. 32:16-19.

23. Bligh, E. G., and W. J. Dyer. 1959. A rapid method of total lipid extraction and purification. Can. J. Biochem. Physiol. 37:911-917.

24. Preiss, J., C. R. Loomis, W. R. Bishop, R. Stein, J. E. Niedel, and R. M Bell. 1986. Quantitative measurement of sn-1,2-diacylglycerols present in platelets, hepatocytes, and ras- and sis-transformed normal rat kidney cells. J. Biol. Chem. 261:8597-8600.

25. Wetsel, W. C., W. A. Khan, I. Merchenthaler, H. Rivera, A. E. Halpern, H. M. Phung, A. Negro-Vilar, and Y. A. Hannun. 1992. Tissue and cellular distribution of the extended family of protein kinase C isoenzymes. J. Cell. Biol. 117:121-133.

26. Tang, E. Y., P. J. Parker, J. Beattie, and M. D. Houslay. 1993. Diabetes induces selective alterations in the expression of protein kinase $\mathrm{C}$ isoforms in hepatocytes. FEBS (Fed. Eur. Biochem. Soc.) Lett. 326:117-123.

27. Henrich, C. J. 1991. Tools for the study of protein kinase C and its isozymes. Focus. 13:133-136.

28. Simboli-Campbell, M., A. M. Gagnon, J. E. Welsh, and D. J. Franks. 1993. Analysis of PKC $\zeta$ in renal cells. Focus. 15:12-15.

29. Ha, K.-S., and J. H. Exton. 1993. Differential translocation of protein kinase $\mathrm{C}$ isozymes by thrombin and platelet-derived growth factor. J. Biol. Chem. 268:10534-10539.

30. Hurrell, D. G., O. Pedersen, and C. R. Kahn. 1989. Alterations in the hepatic insulin receptor kinase in genetic and acquired obesity in rats. Endocrinology. 125:2454-2462.

31. Hotamisligil, G. S., A. Budavari, D. Murray, and B. M. Spiegelman. 1994. Reduced tyrosine kinase activity of the insulin receptor in obesity-diabetes. Central role of tumor necrosis factor- $\alpha$. J. Clin. Invest. 94:1543-1549.

32. Wolf, B. A., J. R. Williamson, R. A. Easom, K. Chang, W. R. Sherman, and J. Turk. 1991. Diacylglycerol accumulation and microvascular abnormalities induced by elevated glucose levels. J. Clin. Invest. 87:31-38.

33. Craven, P. A., and F. R. DeRubertis. 1989. Protein kinase $C$ is activated in glomeruli from streptozotocin diabetic rats. J. Clin. Invest. 83:1667-1675.

34. Inoguchi, T., R. Battan, E. Handler, J. R. Sportsman, W. Heath, and G. L. King. 1992. Preferential elevation of protein kinase C isoform $\beta$ II and diacylglycerol levels in the aorta and heart of diabetic rats: differential reversibility to glycemic control by islet cell transplantation. Proc. Natl. Acad. Sci. USA 89:11059-11063.

35. Cooper, D. R., H. Hernandez, J. Y. Kuo, and R. V. Farese. 1990. Insulin increases the synthesis of phospholipid and diacylglycerol and protein kinase $C$ activity in rat hepatocytes. Arch. Biochem. Biophys. 276:486-494.

36. Nivet, V., J. P. Clot, X. T. Do, V. Barrault, M. Prelot, and D. Durand. 1993 Evidence that growth hormone stimulates protein kinase $\mathrm{C}$ activity in isolated rat hepatocytes. Metabolism. 42:1291-1295.

37. Rossetti, L., D. Smith, G. I. Shulman, D. Papachristou, and R. A. DeFronzo. 1987. Correction of hyperglycemia with phlorizin normalizes tissue sensitivity to insulin in diabetic rats. J. Clin. Invest. 79:1510-1515.

38. Kahn, B. B., G. I. Shulman, R. A. DeFronzo, S. W. Cushman, and L. Rossetti. 1991. Normalization of blood glucose in diabetic rats with phlorizin treatment reverses insulin-resistant glucose transport in adipose cells without restoring glucose transporter gene expression. J. Clin. Invest. 87:561-570.

39. Thakker, J. K., R. DiMarchi, K. MacDonald, and J. F. Caro. 1989. Effect of insulin and insulin-like growth factors I and II on phosphatidylinositol and phosphatidylinositol 4,5-bisphosphate breakdown in liver from humans with and without type II diabetes. J. Biol. Chem. 264:7169-7175.

40. Draznin, B. 1993. Cytosolic calcium and insulin resistance. Am. J. Kidney Dis. 21:32-38.

41. Kanety, H., S. Moshe, E. Shafrir, B. Lunenfeld, and A. Karasik. 1994 Hyperinsulinemia induces a reversible impairment in insulin receptor function leading to diabetes in the sand rat model of non-insulin-dependent diabetes mellitus. Proc. Natl. Acad. Sci. USA. 91:1853-1857.

42. Liu, F. and R. A. Roth. 1994. Insulin-stimulated tyrosine phosphorylation of protein kinase $\mathrm{C} \alpha$ : evidence for direct interaction of the insulin receptor and protein kinase C in cells. Biochem. Biophys. Res. Commun. 200:1570-1577.

43. Arnold, T. P., M. L. Standaert, H. Hernandez, J. Watson, H. Mischak, M. G. Kazanietz, L. Zhao, D. R. Cooper, and R. V. Farese. 1993. Effects of insulin and phorbol esters on MARCKS (myristoylated alanine-rich C-kinase substrate) phosphorylation (and other parameters of protein kinase $\mathbf{C}$ activation) in rat adipocytes, rat soleus muscle and BC3H-1 myocytes. Biochem. J. 295:155164.

44. Freidenberg, G. R., D. Reichart, J. M. Olefsky, and R. R. Henry. 1988 Reversibility of defective adipocyte insulin receptor kinase activity in non-insulin-dependent diabetes mellitus. Effect of weight loss. J. Clin. Invest. 82:13981406.

45. Coghlan, M. P., and K. Siddle. 1993. Phorbol esters induce insulin receptor phosphorylation in transfected fibroblasts without affecting tyrosine kinase activity. Biochem. Biophys. Res. Commun. 193:371-377. 